\title{
The effectiveness of different types of face masks
}

\section{Queen G Wamungu ${ }^{1 *}$, Joan Liverpool ${ }^{2}$, Crystal Loney ${ }^{3}$, Jodene Brevitte ${ }^{3}$ and Nirvani Goberdhan ${ }^{1}$}

${ }^{1}$ Medical Student (MD), Rajiv Gandhi University of Science \& Technology, Guyana (South America)

${ }^{2}$ Adjunct Professor/Director Deskan Restoring Hope, Inc, Guyana (South America)

${ }^{3}$ Green Heart Medical University, Guyana (South America)
Received: 14 September, 2020

Accepted: 21 September, 2020

Published: 22 September, 2020

*Corresponding author: Queen G Wamungu, Medical Student (MD), Rajiv Gandhi University of Science \& Technology, Lot 7 Middleton Street, Campbellville, Georgetown, Guyana (South America), Tel: +(592)-630-9825;

E-mail: queengajuu@yahoo.fr; gajuqueen@gmail.com ORCID: https://orcid.org/0000-0002-7949-0924 https://www.peertechz.com

Check for updates

\section{Introduction}

The Novel Coronavirus (COVID-19) continues to be a major health burden in many countries around the world with astonishing reports of fatalities. The burden on the health care systems around the world has been tremendous with a death toll of over 190,000 deaths in the US [1]. According to the World Health Organization (WHO), the Sars-CoV-2 virus that causes COVID-19 disease is spread via respiratory droplets [2]. According to a study published by Durgesh Sinha and Nicholas Klahn, from Tempa University and Rowan College at Burlington college respectively, on April $12^{\text {th }}, 2020$, titled "Mathematical modeling study of the 2020 Covid-19 outbreak in the United States", $40 \%$ - $80 \%$ of Covid-19 transmission arise from people who are pre-symptomatic or asymptomatic [3].

In addition to social distancing and regular hand washing/ sanitizing techniques, WHO recommends that everyone above age 2 years old should wear a face mask to prevent further spread of the SARS-CoV-2 [4].

\section{Types of face masks}

[5] Face masks are divided into two general categories; Medical and Non-medical. Medical face masks include professional respirators (N-95), surgical and non-surgical face masks. Non-medical face masks consist of homemade masks, and filtered masks.

\section{Five (5) Factors that affect the efficacy of face masks against SARS-CoV-2?}

Size of respiratory droplets: It is important to note that SARS-CoV-2 viral particles are expelled from the respiratory tract as relatively large droplets whenever an infected individual talks, coughs, or sneezes, less so by simply breathing. Larger droplets fall to the ground while smaller droplets are generally suspended in the air then evaporate a few seconds later, downsizing to smaller droplets of about 5-10 micrometers that can float longer in the air [6]. Therefore, for masks to be efficacious, they must be able to filter particles of the aforementioned sizes. It is therefore important to consider the type of material used to make the face masks and what each is approved for filtering.

Mode of the expulsion of respiratory droplets: Earlier studies suggested that the SARS-Cov-2 virus was spread mainly through coughing, but recent studies suggest that talking is also an important mode of transmission. The louder you speak, the more droplets are expelled and therefore there is a higher viral load transmission and an increased chance of transmitting the SARS-Cov-2 virus [6]. Coughing will force droplets into the air at more considerable force, allowing them to travel farther distances and widening the infectious perimeter around the infected party.

Material of face masks: The Centers for Disease Control and Prevention National Institute for Occupational Safety and Health (NIOSH) and the Occupational Safety and Health Administration (OSHA) regulate N95 respirators. They are tested for fluid resistance, filtration efficiency (particulate filtration efficiency, and bacterial filtration efficiency), flammability and biocompatibility [7]. Non-medical masks are made from different materials and designs with or without filter papers. The combination of material, amount of layers, the presence of filters and how tightly the material is woven will affect the efficacy of the face mask [8].

Fit of face masks: The fit of the masks is very important to consider for protecting yourself against COVID-19. It should fit tightly enough to create a seal but comfortably enough to prevent frequent repositioning. 
"In general, a mask is less helpful or counterproductive if it is not covering the nose and mouth, such as worn down around the neck for extended periods of time or if it is poorly fitting to the point that it requires frequent adjustment, which brings your hands close to your face repeatedly," said Dr. George Anesi, director of the Medical Critical Care Bioresponse team at Penn Medicine [9].

The technique used in donning, removing and reusing face masks: WHO recommends extended use (up to 6 hours) over reuse but in extenuating circumstances, such as short supply, face masks can be re-processed (sterilized) and reused. Extended use is accepted if the face mask is damaged, soiled, or wet [10]. The diagram below [Figure 1] was recommended for guiding the reuse of face masks in the medical setting. For nonmedical settings, cloth masks should be washed frequently for the most effective outcome [8].

\section{Efficacy of Non-Medical face masks in preventing the spread of COVID-19}

The use of non-medical face masks outside of the healthcare setting is recommended but may be inadequate in preventing the spread of the novel coronavirus says a study conducted by the College of Public Health Medicine Evidence-based COVID-19 Task Team. They stated that not much evidence has been garnered pertaining to the efficacy of cloth masks in comparison to their medical counterparts. They also stated with moderate certainty that the number of cases increases with the use of cloth masks [11].

Non-medical masks are readily available from many local sources and therefore impossible to adequately regulate, which seems to be a part of the problem. The goal of communitywide mask-wearing is to quell the spread of the COVID-19 by decreasing the number of respiratory droplets that are spread by pre-symptomatic and asymptomatic carriers [12], says the European Center for Disease Control.

The percentage efficacy of some household non-medical masks has been stated by one preprints article to be "between a $49 \%$ and $86 \%$ filtration rate for $0.02 \mu \mathrm{m}$ exhaled particles whereas surgical masks filtered $89 \%$ of those particles." Additionally, they mentioned a laboratory testing which showed "household materials had 3\% to $60 \%$ filtration rate for particles in the relevant size range, finding them comparable to some surgical masks" [6].

\section{Extended use, re-use or reprocessing of single-use surgical masks and filtering facepiece respirators should be considered only as a last-resort measure during critical shortages. \\ Evidence in this area is limited and guidance is inconsistent in certain areas.}

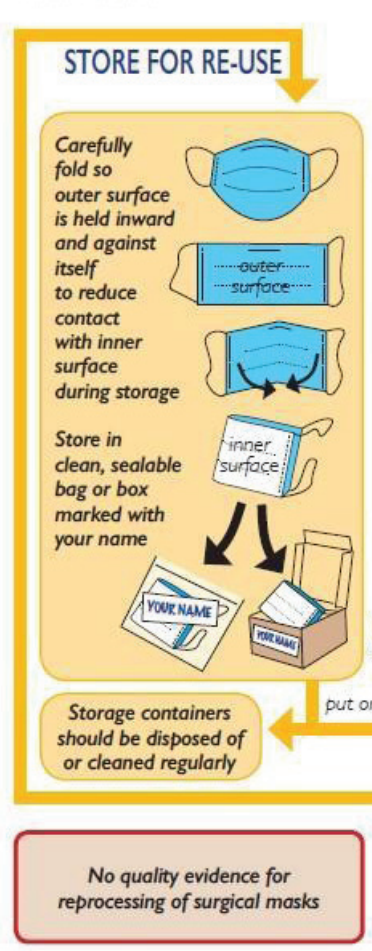

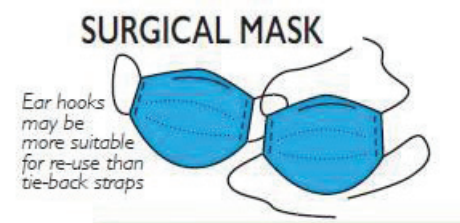

FFP RESPIRATOR
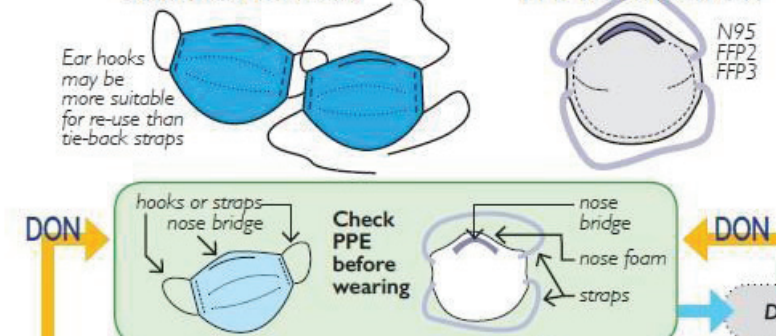

DON DISCARD
Damoged Damaged
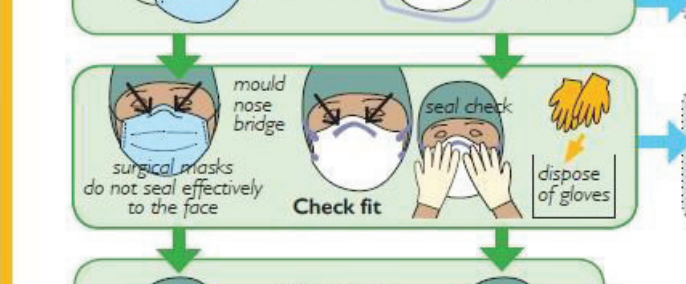

DISGAR

Can no longer be
properly properly
fitted
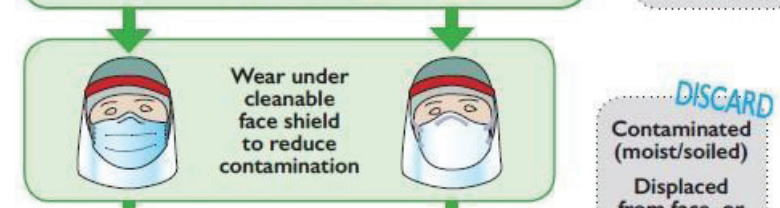

Contaminated
(moist/soiled)

Displaced from face, or front touched Difficult to breathe through

After AGP *US CDC and ECDC recommend discarding and not reprocessing respirators

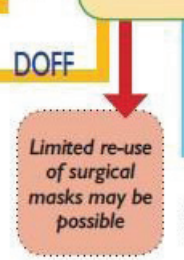

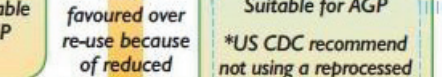
$\begin{gathered}\text { of reduced } \\ \text { risk of contact }\end{gathered}$
$\begin{gathered}\text { not using a reprocessed } \\ \text { respirator while }\end{gathered}$
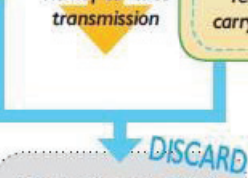

After leaving cohort area after use in AGPs (subject to manufacturer guidance)

ing out an AGP

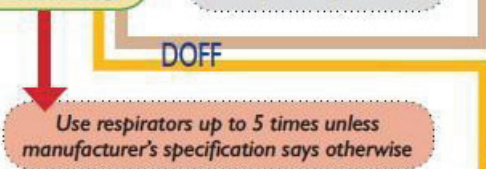

STORE FORRE-USE STORE

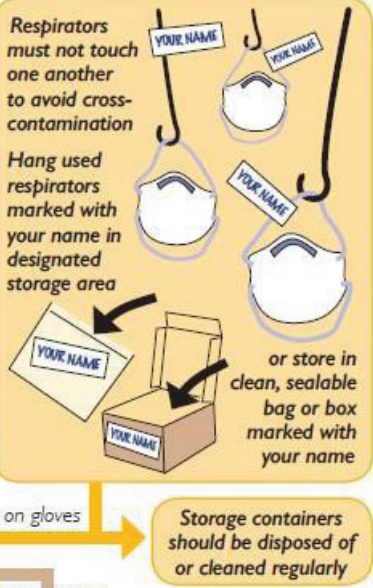

REPROCESS

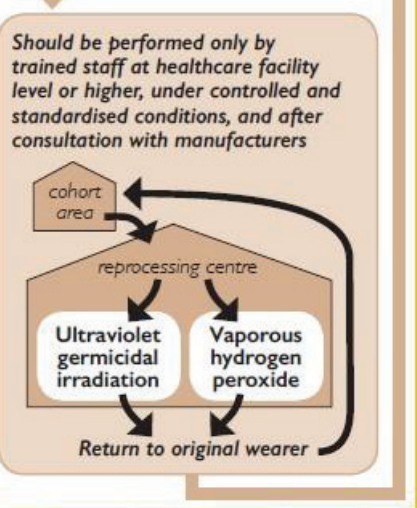


According to a study published by Abhiteja Konda and others, on April $24^{\text {th }}, 2020$, titled "Aerosol Filtration Efficiency of Common Fabrics Used in Respiratory Cloth Masks", the efficiency of homemade masks improved when multiple layers were used and when using a specific combination of different fabrics [8]:

0 The function of aerosol particulate sizes in the $10 \mathrm{~nm}$ to $10 \mu \mathrm{m}$.

o Filtration efficiency of single layer: 5-80\% and 5-95\% for particles size $<300 \mathrm{~nm} \&>300 \mathrm{~nm}$.

o Filtration efficiency of hybrids (cotton-silk, cottonchiffon, cotton-flannel): $>80 \%$ (for particles $<300 \mathrm{~nm}$ ); and $>90 \%$ (for particles $>300 \mathrm{~nm}$ ).

0 The enhanced performance is due to the combined effect of mechanical and electrostatic-based filtration.

Ultimately, WHO recommends the use of tightly-woven fabric masks made of linen or cotton consisting of three or more layers. Additional worldwide recommendations include frequent mask washing, comfortable fit, and proper removal techniques [13].

While the fight continues to quantify the benefit of nonmedical masks, a few setbacks still remain. Many versions of non-medical masks provide an inadequate seal to the mouth and nose, there is poor fluid resistance and frequent readjustment is required [14]. Poor compliance and misinformation about their efficacy are also contributing factors. Regardless of these factors, they are effective in reducing the number of droplets spread when compared to the use of no mask at all [15].

\section{Efficacy of medical masks in preventing the spread of COVID-19 Table 1}

A review in the International Journal of Nursing Studies [titled 'A rapid systematic review of the efficacy of face masks and respirators against coronavirus and other respiratory transmissible viruses for the community], health care workers and sick patients' found that there is benefit in using face mask for healthcare workers and community members. The article stated that "In the community, masks seemed to be effective with and without hand hygiene and both together are protective." It also stated that continued use of face masks and respirators by health care workers throughout their entire shift had protective benefits against contracting and spreading the virus.

$[19,20]$. Due to their scarce supply, WHO suggests that professional respirators should only be reserved for healthcare workers in direct contact with COVID-19 patients and procedural or surgical face masks can be worn by healthcare workers, not in direct contact with COVID-19 patients [4].

\section{Efficacy of medical masks against COVID-19 compared to that of non-medical face masks}

The results from a comparison of surgical and homemade masks against bacterial and viral aerosols from the review article in the International Journal of Nursing mentioned above showed that "the median fit factor of homemade masks was one half that of surgical masks. It went on to say that both surgical and homemade masks decreased the number of microorganisms expelled by the test subjects but the surgical masks were 3 times more effective $[19,20]$.

Table 1: Showing the Efficacy of Medical Masks against COVID 19 Compared to that of Non-Medical Face Masks.

\begin{tabular}{|c|c|c|c|}
\hline & Surgical Masks & Respirators (N95, FFP) & Cloths Masks \\
\hline $\begin{array}{l}\text { Testing and } \\
\text { Approval [16] }\end{array}$ & Classified by ASTM & Evaluated and certified by $\mathrm{NIOSH}$ & $\begin{array}{l}\text { Have not been evaluated or tested to } \\
\text { recognized standards }\end{array}$ \\
\hline Purpose & $\begin{array}{l}\text {-Also known as FRSM. } \\
\text {-Provide a barrier to splashes and large } \\
\text { droplets impacting the wearer's mouth, nose, } \\
\text { and respiratory tract [17]. } \\
\text {-Do not protect against smaller droplets. }\end{array}$ & $\begin{array}{c}\text { - Type of respirator } \\
\text { - FFP: UK equivalent of N95 (in the USA). } 3 \text { categories: } \\
\text { FF1, FFP2, FF3 } \\
\text { - Provide more protection than surgical masks. } \\
\text { - Can filter out both large and small particles when the } \\
\text { wearer inhales [17]. }\end{array}$ & $\begin{array}{l}\text { - Sewn and non-sewn types } \\
\text { - Intended to trap droplets that are released } \\
\text { when the wearer talks, coughs, or sneezes. } \\
\text { - Can use pillowcases, t-shirts, bandanas, } \\
\text { scarves to make them. } \\
\text { - Thicker, tightly woven cotton fabrics are } \\
\text { preferred [8]. }\end{array}$ \\
\hline Fit (Face Seal) [16] & Loose-fitting & Tightly fitted to the face & Fits against face \\
\hline $\begin{array}{l}\text { Fit testing } \\
\text { requirement }\end{array}$ & No & Yes & No \\
\hline Filtration & $75 \%[6]$ & $\begin{array}{l}\text { Filters out } 95 \% \text { of airborne particles (large and small) } \\
\qquad[16]\end{array}$ & $\begin{array}{l}-3-60 \%[6] \\
\text { - High thread-count fabric combined with a } \\
\text { high-electrostatic fabric filter aerosols most } \\
\text { effectively [8] }\end{array}$ \\
\hline Use limitations [16] & Disposable, meant for one-time use. & Generally for a single-time use & $\begin{array}{l}\text {-May be difficult to breathe through the fabric } \\
\text {-Wash between uses }\end{array}$ \\
\hline Intended Users [18] & $\begin{array}{l}\text { - Healthcare workers, and patients in } \\
\text { healthcare settings. }\end{array}$ & Health care workers. & General public \\
\hline When to wear [18] & $\begin{array}{l}\text { - During single or multiple patients' } \\
\text { interactions or routine health procedures. - } \\
\text { Surgical masks are also recommended when } \\
\text { N95s are not available. }\end{array}$ & $\begin{array}{l}\text { Recommended for use by healthcare workers providing } \\
\text { care for patients with Covid-19, and performing } \\
\text { procedures putting them more at risk of virus exposure. }\end{array}$ & $\begin{array}{c}\text { Recommended for persons who cannot } \\
\text { perform social distancing: } \\
\text {-When coughing or sneezing. } \\
\text { - In public transportations, grocery stores, } \\
\text { pharmacies, and other essential businesses.. }\end{array}$ \\
\hline
\end{tabular}




\section{Conclusion}

Based on the literature reviewed, it is safe to say that wearing face masks at the community level and in medical settings will decrease the spread of COVID-19 by:

1. Preventing Sars-CoV-2 droplets from leaving the infected wearer and entering the environment.

2. Preventing Sars-CoV-2 droplets from entering the respiratory tract of the uninfected wearer .

Face masks can be used as personal protective equipment (PPE) or for blocking infected droplets produced by the wearer.

Some face masks can act as both PPE and a means of preventing droplet transmission from the wearer (Surgical Masks, N95) while others will only act as a PPE (N95 with one-way outlet valves) and do not protect the public from the wearer.

Others, such as the cloth mask will protect the public from the infected wearer but offer less protection for the wearer from the infectious public.

In summation, after a thorough review of 20 literatures, we have determined that the use of face masks will greatly reduce the spread of the SARS-CoV-2 virus at the community level and in medical settings, by reducing viral droplets transmission.

\section{Acknowledgments}

Crystal Loney: GreenHeart Medical University, contributing author.

Jodene Brevitte: GreenHeart Medical University, contributing author.

Nirvani Goberdhan: Rajiv Gandhi University of Science \& Technology, contributing author.

Dr. Joan Liverpool CHES, Ed.D, MD: Adjunct Professor/ Director Deskan Restoring Hope, Inc.

\section{References}

1. COVID-19 Dashboard by the Center for Systems Science and Engineering (CSSE) at Johns Hopkins University (JHU). Johns Hopkins University \& Medicine Corona Resource Center. Johns Hopkins University \& Medicine 2020. Link: https://bit.ly/35VbNcn

2. Transmission of SARS-CoV-2 (2020) Implications for Infection Prevention Precautions. World Health Organization. Link: https://bit.ly/2FSLqJh

3. Durgesh S, Klahn N (2020) Mathematical Modeling Study of the 2020 CoVID-19 Outbreak in the United States. SSRN Electronic. Link: https://bit.ly/3kAUkKq
4. Alex B, Weatherspoon D (2020) What Face Mask to Use during the COVID-19 Pandemic. Medical News Today, MediLexicon International. Link: https://bit.ly/3iPNOPH

5. Mask Types. Mask Types | University of Maryland Medical System. Link: https://bit.ly/35Q6WcJ

6. Howard J, Huang A, Li Z, Tufekci Z, Zdimal V, et al. (2020) Face Masks Against COVID-19: An Evidence Review. Preprints. Link: https://bit.ly/3cioqQ1

7. N95 Respirators, Surgical Masks, and Face Masks. Personal Protective Equipment for Infection Control | U.S. Food \& Drug Administration. Link: https://bit.ly/3iQqI0y

8. Konda A, Prakash A, Moss GA, Schmoldt M, Grant GD, et al. (2020) Aeroso Filtration Efficiency of Common Fabrics Used in Respiratory Cloth Masks. ACS Nano 14: 6339-6347. Link: https://bit.ly/3ksgRcu

9. Chrissy C (2020) Are You Wearing a Face Mask Correctly? Common Mistakes to Avoid. TODAY.com. Link: https://on.today.com/2FPqbIB

10. The Centre for Evidence Based Medicine (2020) Extended Use or Re-Use of Single-Use Surgical Masks and Filtering Facepiece Respirators: A Rapid Evidence Review. Link: https://bit.ly/2FUJccw

11. Cochrane South Africa and South African Medical Research Council Health Systems Research Unit, and College of Public Health Medicine Evidencebased COVID-19 Task Team. "BRIEF REPORT OF RAPID REVIEW: Should cloth masks be used by the general public for preventing transmission of SARSCoV-2?, 2020. Link: https://bit.ly/3mAjIID

12. European Centre for Disease Prevention and Control. Cloth masks and mask sterilisation as options in case of shortage of surgical masks and respirators. 2020. Link: https://bit.ly/33KB1rs

13. When and How to Use Masks (2020) World Health Organization. Link https://bit.ly/2FRKOin

14. Cloth (Fabric) Masks as an Alternative to N95 Respirators in a Health Care Setting: Supplemental Information. Ontario Health Quality, Queen's Printer for Ontario. 2020. Link: https://bit.ly/33L5Qw7

15. Use Masks to Help Slow Spread (2020) Centers for Disease Control and Prevention, Centers for Disease Control and Prevention. Link: https://bit.ly/33LhCqb

16. Respirators, Medical Masks, and Non-Medical Masks. Canadian Centre for Occupational Health \& Safety 2020. Link: https://bit.ly/3cgMvGZ

17. The Center for Evidence-Based Medicine (2020) What Is the Efficacy of Standard Face Masks Compared to Respirator Masks in Preventing COVIDType Respiratory Illnesses in Primary Care Staff?. Link: https://bit.ly/33PBDMk

18. Katie J (2020) Mask Comparisons. Hays Companies. Link: https://bit.ly/32LkkNk

19. Maclntyre CR, Chugthtai AA (2020) A Rapid Systematic Review of the Efficacy of Face Masks and Respirators against Coronaviruses and Other Respiratory Transmissible Viruses for the Community, Healthcare Workers and Sick Patients. Int J Nurs Stud 108: 103629. Link: https://bit.ly/2RKs4ZA

20. "Face Masks". Efficiency in Group Practice. 2019. Link: https://bit.ly/35UzT76

Copyright: @ 2020 Wamungu QG, et al. This is an open-access article distributed under the terms of the Creative Commons Attribution License, which permits unrestricted use, distribution, and reproduction in any medium, provided the original author and source are credited. 